\title{
||||||||||||||||||||||||||||||||||||||||||||||||||||||||||||||||||||.
}

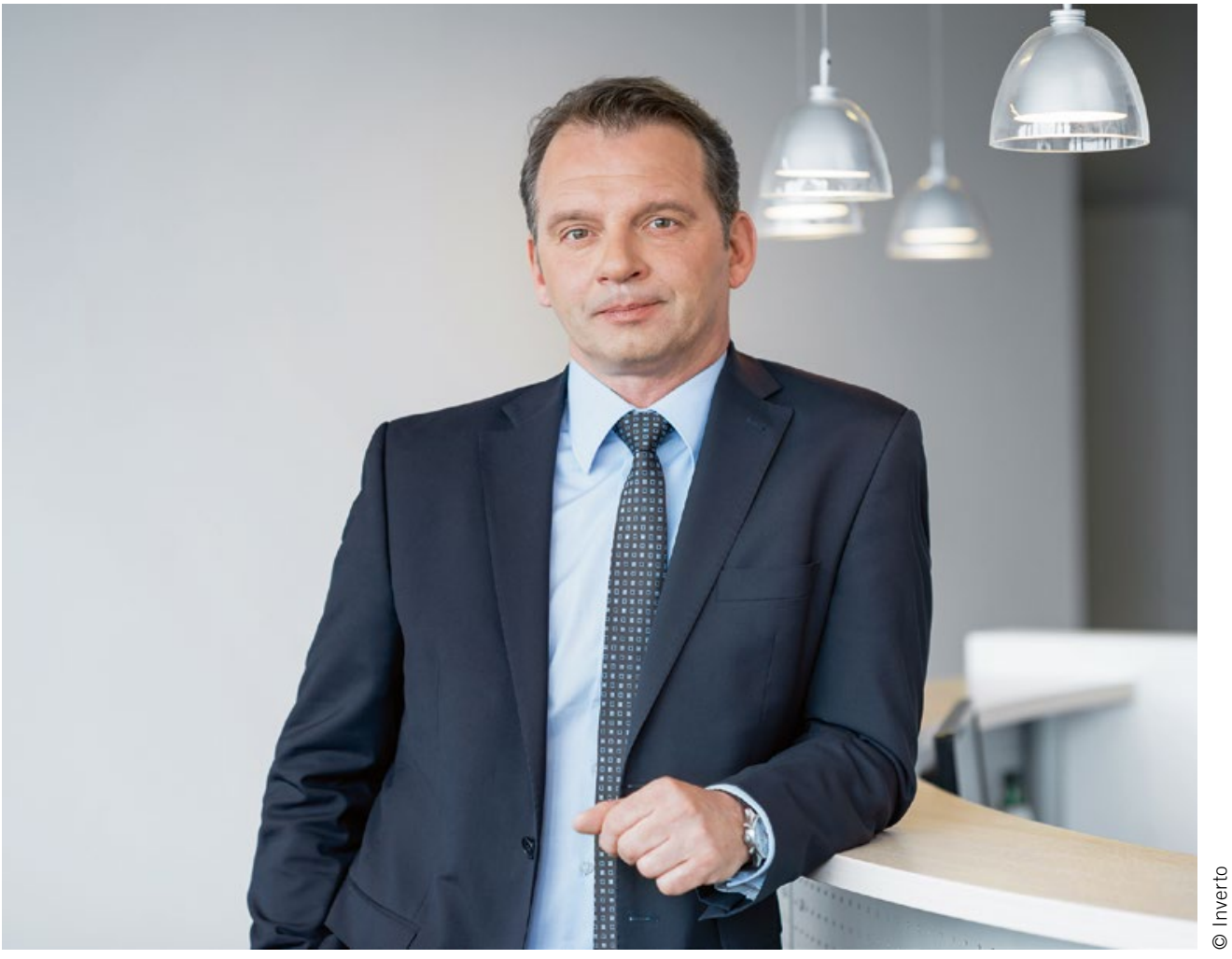

Dipl.-Kfm. (FH) Frank Welge Managing Director of the Munich Office of Inverto $\mathrm{GmbH}$ (a Boston Consulting Group Company)

\section{Thinking Ahead on the Road to E-mobility}

One of the most important things new drivers learn during their driving lessons is to look and think ahead while driving. And the ability to think ahead is also what makes successful car manufacturers and suppliers leaders in their technological field. This skill is urgently needed today, with the automotive industry on an inexorable path from combustion engines to electric mobility. The change will be far-reaching and, in the face of mounting pressure from European and Chinese legislators, is likely to accelerate in the coming years. Consumer demand for vehicles with alternative drives is also increasing rapidly.

Meeting this demand is one of the major challenges facing the market today - as is clear from reports of delivery delays and long waiting times, sometimes of up to several months. Car manufacturers and their suppliers need to rethink their supply chains in order to realize the opportunities for growth that this change brings with it. There are such big differences between vehicles with combustion engines and those with electric drives that the change will not be achievable using established structures.

In order to re-organize the supply chains, automotive development and procurement teams must work together at an early stage. How is demand shifting? Which new raw materials and components are required? Who can supply them in sufficient volume and quality? Careful analysis of these aspects will be needed in order to make decisions about outsourcing or in-house production, and about which new strategic partnerships can be established.

The field of e-mobility has not yet been fully mapped out: These are pioneering times. There are now opportunities for companies who usually deal with the traditional components of the combustion engine to work in collaboration with others with partners from the electric engineering or software industries, for example - to develop innovative solutions and establish themselves as suppliers for e-mobility as well as combustion engines.

Of course, it is not easy to invest large sums in research and development of new components, particularly for smaller specialists. However, these experts do have the advantage of being able to rely on a network within the industry, and already enjoying the trust of their customers. With this security behind them, these second- and third-tier suppliers should actively seek out new trends and possible partners, including in sectors other than these ones of the automotive industry. In this way, thinking ahead about e-mobility can become a key to success. 